\title{
Long-Term Variations of Temperature and Precipitation in the Megacity of Istanbul for the Development of Adaptation Strategies to Climate Change
}

\author{
Hüseyin Toros, ${ }^{1}$ Mohsen Abbasnia, ${ }^{1}$ Mustafa Sagdic, ${ }^{2}$ and Mete Tayanç ${ }^{3}$ \\ ${ }^{1}$ Department of Meteorology, Istanbul Technical University, Maslak, 34469 Istanbul, Turkey \\ ${ }^{2}$ Department of Social Studies, Faculty of Education, Ylldiz Technical University, 34210 Istanbul, Turkey \\ ${ }^{3}$ Department of Environmental Engineering, Marmara University, Göztepe, Istanbul, Turkey \\ Correspondence should be addressed to Mohsen Abbasnia; abbasnia@itu.edu.tr
}

Received 5 June 2017; Revised 21 September 2017; Accepted 17 October 2017; Published 19 November 2017

Academic Editor: Julio Diaz

Copyright (C) 2017 Hüseyin Toros et al. This is an open access article distributed under the Creative Commons Attribution License, which permits unrestricted use, distribution, and reproduction in any medium, provided the original work is properly cited.

\begin{abstract}
Istanbul, as one of the four anchor megacities of Europe, has shown a rise of $0.94^{\circ} \mathrm{C}$ in average annual temperature over the long period of 1912-2016 under impacts of anthropogenic climate change. A notable increase in temperatures has started after the 1940s, which is in parallel with the beginning of industrialization era in Istanbul. This warming is associated with an extensive population growth and accompanied the decrease in vegetation cover. Increasing in minimum series of temperature is more evident than maximum values and the rising rate of temperature values has been more pronounced during recent decades. The first significant upward trend in precipitation series has periodically started in 1920s, while there has been a stable trend from 2001 till today. The daily average of rainfall amount increased with a mean value of $58 \mathrm{~mm}$ during the total study period. Rising rate of daily maximum precipitation has been more evident in the last 3 decades, which is shown by the increased frequency of heavy rainfall. In this regard, both of the temperature and precipitation series had higher mean values $\left(13.9^{\circ} \mathrm{C}\right.$ and $\left.878 \mathrm{~mm}\right)$ for the final period (1965-2016) compared to the mean values $\left(13.6^{\circ} \mathrm{C}\right.$ and $\left.799 \mathrm{~mm}\right)$ belonging to the first period (1912-1964).
\end{abstract}

\section{Introduction}

Modernization and industrialization and their socioeconomic effects have caused an increase in rapid urbanization all over the world. The probability of climate variability and climate change especially in megacities is the cause of great concern among scientists, governments, and lawmakers. Uncontrolled changes in demographic values, land-use area, vehicle and industrial product types, and building features can play an important role in regional climate change and can produce further problems in settlement areas due to more occurrences of climatic disasters. Previous researchers represent that since the beginning of the 20th century, average global temperature has increased about $0.6^{\circ} \mathrm{C}$ [1]. According to the 5th assessment report (AR5) of the Intergovernmental Panel on Climate Change (IPCC), global average temperature has shown a $0.85^{\circ} \mathrm{C}$ increase over the period of $1800-2012$ and this trend of global warming is predicted to likely increase during the 21st century under the all Representative Concentration Pathways scenarios [2]. Thus, climate change can be a serious threat to sustainable development, particularly in megacities in terms of economic, social, and environmental effects. From the beginning of the industrial revolution age to the present, the excessive use of fossil fuel for the sake of economic growth has affected the delicate balance of the atmosphere by leading to an increase in greenhouse gas emissions. So, it is accepted today that human lifestyle and the increasing demands on natural resources are the main causes of climate change. Global climate change will have diverse impacts on human health because the health of the human population depends fundamentally on the conditions of social and natural environments [3]. On the other hand, urban heat island (UHI) is related to the fast urbanization and industrialization of the cities. In this case, a 
good understanding of rising trends in population and water consumption is necessary to prevent any water shortage in the coming decades.

One of the consequences of climate change is the increasing frequency of extreme events $[4,5]$ such as floods, droughts, heat waves associated with negative effects on the environment, losing the life and property, and disturbance of human climate comfort. For example, many heat-related deaths occurred during the heat wave events in Chicago in 1995, in Western Europe in 2003, and in East Asia in 1994 [68]. Also, recent studies revealed significant worldwide warming and a general increase in the frequency and persistence of extreme temperature and precipitation events (e.g., [9-13]). So far, extensive researches have been conducted to detect the effects of climate change on climatic variables at a regional scale. Meanwhile, a comprehensive assessment of the global warming impacts on climatic parameters is necessary for any regions, especially urban areas which are affected more by negative effects of urbanization and anthropogenic on the environment [14]. In the study area, some studies have been investigated to understand climate change impacts by focusing on temperature and precipitation variability. In this connection, one of the conclusions is that these studies agree on the urban development influence on the temperature and precipitation values. Tayanç et al. [15] carried out a study using temperature and precipitation data for the period of 1950-2004 to classify the weather stations into two groups according to their populations under climate change over Turkey. These results showed that a significant warming trend is observed in both urban and suburban weather stations in the last decade and the variability of precipitation time series in the urban area is generally larger than rural area and urban weather stations are experiencing more frequent and severe droughts and floods hazards. Toros [16] found a significant warming trend in both annual maximum and minimum temperature parameters. Increasing trends in warm periods are comparatively stronger than cold periods, especially in the maximum temperatures. Toros [17] indicated that there is a general decreasing tendency in the total annual precipitation over more than $34 \%$ of weather stations of Turkey. Also, Türkeş et al. [18] indicated that all 3 air temperature series, minimum, maximum, and average, have increased after the 1980s over Turkey. In this case, there is a negative trend in precipitation parameter along with the positive trend in temperature parameter in Turkey, which may significantly affect water sustainability regionally. There is no doubt that more water supply facilities will be needed due to a reduction in rainwater and increase in evaporation under warmer conditions as well as increasing rate in the population with more water demands.

In this regard, the reports of IPCC demonstrate that each of the last three decades has been warmer than all the previous decades [19]. Also, rising inland temperatures are larger than the sea temperatures, mainly owing to the landuse characteristics and urban heat island. The demographic studies of United Nations [20] showed that the proportion of the world population in urban areas has increased from a mere $13 \%$ in 1900 to $54 \%$ in 2014 . This is showing that authorities need to prepare and develop adaptation strategies for the urban areas, especially megacities. Therefore, this study aimed to evaluate the climate variability in Istanbul, one of the largest and most populated megacities in the world, under the light of anthropogenic effects and climate change consequences; the study is carried out based on 105 years of recorded meteorological data of the weather station Kandilli. In this work, various statistical analyses are used to detect the long-term climatic changes in the temperature and precipitation time series. Thus, the results of this study relying on the long-term meteorological data can be a reference and guidance for researchers and decision-makers of urban planning, climate change adaptation, and management owing to the strategic location of Istanbul.

\section{Study Area and Data}

The megacity of Istanbul with the geographical coordinates of $28^{\circ} 57^{\prime} 53^{\prime \prime} \mathrm{E}$ and $41^{\circ} 01^{\prime} 07^{\prime \prime} \mathrm{N}$ is the biggest city in Turkey and is one of the most populous cities in the world. Istanbul is geographically located in the northwest of Turkey and the weather station of Kandilli is in the middle of the Asian side of this city (Figures 1(a) and 1(b)). This megacity is the heart of Turkey owing to the industry, commercialization, culture, and tourism. This city covers a total area of approximately $5,400 \mathrm{~km} 2$ and has a lot of hills with the highest point of $540 \mathrm{~m}$ at the Aydos Hill [21]. Owing to the effects of industrialization in Turkey, significant environmental impacts have started to be seen after the 1970s. Today, almost every kind of environmental pollution can be found around the greater Istanbul metropolitan area. Istanbul's climate is usually warm and dry in summer and cold and wet in winter. Istanbul contains many hills and valleys topographically. Thus, Istanbul's temperature and precipitation are changed from one side to the other. The average annual temperature is about $13.8^{\circ} \mathrm{C}$ with a monthly maximum of $22.8^{\circ} \mathrm{C}$ in August and a monthly minimum of $5.3^{\circ} \mathrm{C}$ in February. The total annual precipitation is $837.5 \mathrm{~mm}$ with a monthly maximum of $128.4 \mathrm{~mm}$ in December and a monthly minimum of $31.9 \mathrm{~mm}$ in July. The population of Istanbul is about 15 million people according to the results of population registration system in 2016 [22]. The trend of population growth in Istanbul shows an increasing tendency from 2000 to 2017 (Figure 1(c)). Also, it is possible to see the different views of Istanbul for vegetation changes by using the Normalized Difference Vegetation Index (NDVI) over the time (Figure $1(\mathrm{~d})$ ). This variability can be the driving force of extreme meteorological events with damaging effects under climate change conditions.

In this study, we used climatic data of Kandilli station which is located in a park and its neighboring site is an area without urban density. This is an advantage for recording the weather data which has not been affected by urban activities and the results of the data analysis can show reliable climate variability representing the region. For the quality analysis of the data, several methods are considered. There is no information about the history of meteorological instruments which have been used to record the data at the Kandilli station. Some of earlier records of instruments which are presented by Erinç [23] are neither complete enough to be used in the analysis nor fully available from any other source 


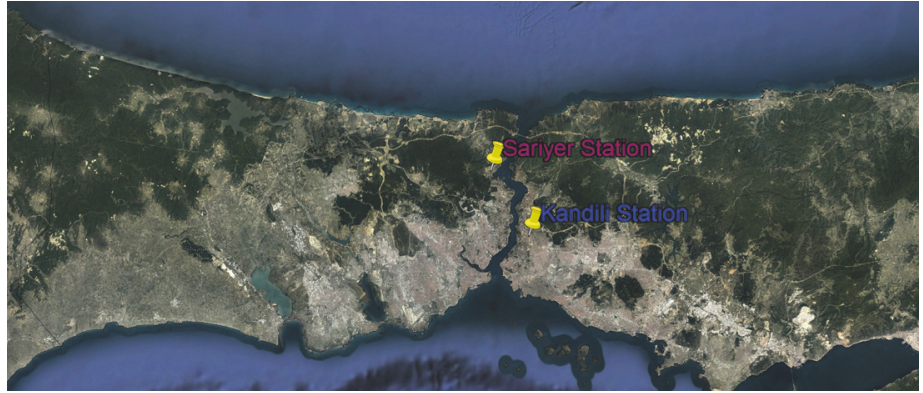

(a)

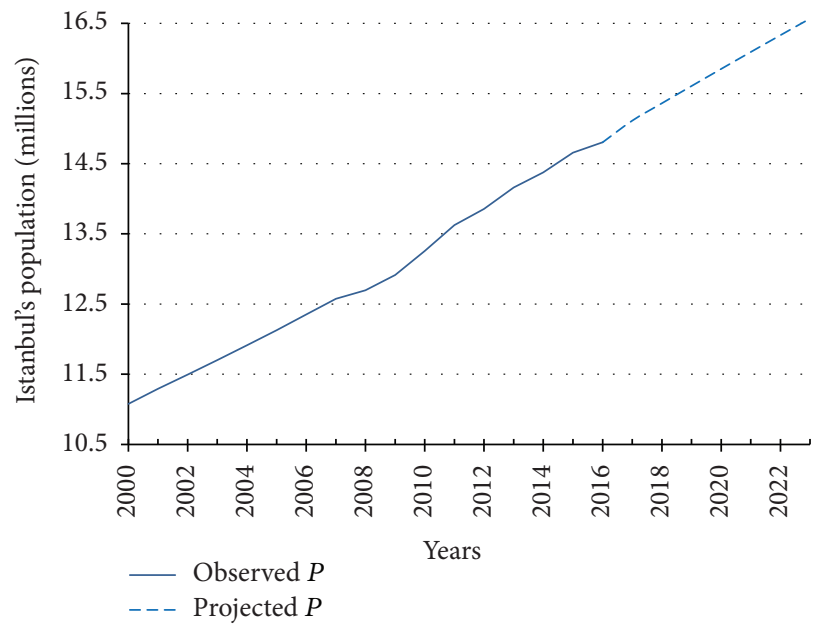

(c)

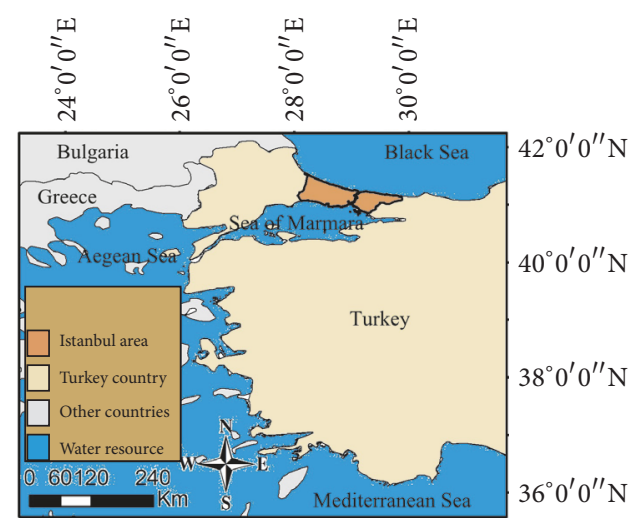

(b)

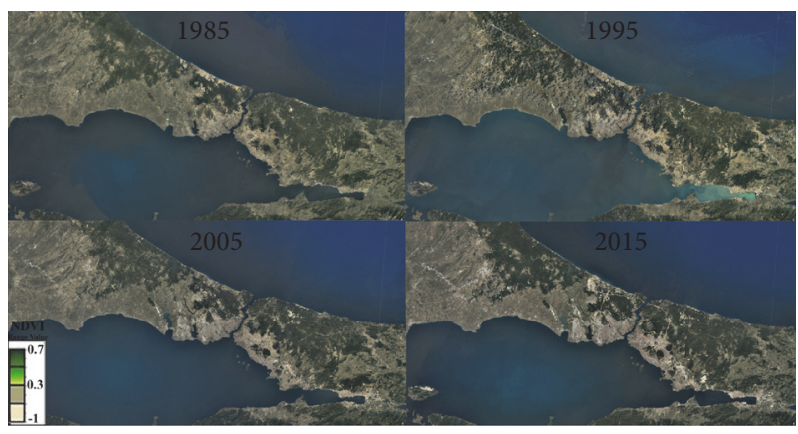

(d)

FIGURE 1: Geographical location of Istanbul (a) and Turkey (b); population growth (c) and NDVI changes (d).

[24]. Thus, we decided to use a data period of 1912-2016 that is larger than a century, which has high-quality data and can provide information about climate change. Climate change is a long-term continuous change (increase or decrease) to average weather conditions (e.g., average temperature) or the range of weather (e.g., more frequent and severe extreme storms). Both can also happen simultaneously. Therefore, in the present study, the meteorological data of Kandilli station due to the valuable longest period of recording the observational data from 1912 to 2016 is used for a comprehensive assessment of the climate fluctuations in Istanbul area in advance to global climate change effects. In this case, the longterm daily minimum, average, and maximum temperature and total annual precipitation time series are prepared from meteorological service of Kandilli station which is situated at Asian part of Istanbul (see Figure 1(a)).

\section{Methodology}

Different time series of meteorological data at the station scale of Kandilli including daily temperature and precipitation are considered for analysis of the climate change effects in Istanbul city over the time. First, reliability and accuracy of these data at the significance level of 95 (Table 1) are checked via SPSS software for based quality tests such as Run test of randomness, Kolmogorov-Smirnov test of normality, and Levene's test of homogeneity. In this case, Run test is used to test whether the data time series are random or not [25]. Also, K-S test is applied to check whether the data time series is normally distributed (or bell-shaped) with 0 mean, 1 standard deviation, and a symmetric bell-shaped curve [26]. Finally, Levene's test is used to assess if the groups have equal variances or to test the assumption of homogeneity of variance by comparing climatic series of the Kandilli station over the time and with its nearby station called Sariyer (refer to Figure 1(a)) inside of Istanbul area [27]. Thence, the nonparametric Mann-Kendall (MK) trend test and statistical regression analysis are used to discover variability and trend in the data time series. The result of MK test shows any increasing or decreasing trends in the data time series, whereas a value of $u(t)$ higher than 1.96 shows a positive trend and a value of $u(t)$ lower than -1.96 shows a negative trend at the significance level of $95 \%[28,29]$. The Mann-Kendall test examines whether to accept the null hypothesis $\mathrm{H} 0$ (shows no monotonic trend) or the alternative hypothesis $\mathrm{H} 1$ (shows monotonic trend). As (1) shows, the 
MK test is applicable in cases when the data values $X i$ of a time series can be assumed to obey the model.

$$
X i=f(t i)+\varepsilon i,
$$

where $f(t)$ is a continuous monotonic increasing or decreasing function of time; the residuals $\varepsilon i$ can be assumed to be from the same distribution with zero mean.

Then, an upward or downward trend is given by a positive or negative value of $Z$. For this purpose, at first, the variance of $S$ is computed using the following equation:

$$
\operatorname{VAR}(S)=\frac{n(n-1)(2 n-5)-\sum_{i=1}^{m} t(t-1)(2 t+5)}{18},
$$

where $m$ is the number of tied groups; $t$ is the number of data values in the $i$ group. Then the values of $S$ and $\operatorname{VAR}(S)$ are used to compute the MK test statistic of $Z$, as is present in (3) $(Z: a, b, c)$ :

$$
\begin{aligned}
& Z_{a}=\frac{S-1}{\sqrt{\operatorname{VAR}(S)}}, \quad \text { if. } S>0, \\
& Z_{b}=0, \quad \text { if. } S=0, \\
& Z_{c}=\frac{S+1}{\sqrt{\operatorname{VAR}(S)}}, \quad \text { if. } S<0 .
\end{aligned}
$$

Moreover, remote sensing phenology studies use data gathered by satellite sensors which measure wavelengths of light absorbed and reflected by green plants. Certain pigment in plant leaves strongly absorbs wavelengths of visible light (red). The leaves themselves strongly reflect wavelengths of near-infrared light, which is invisible to human eyes. This has long been used to monitor the vegetation and changes in the vegetation of the entire Earth. Although there are several vegetation indices, one of the most widely used is the Normalized Difference Vegetation Index (NDVI) (see (4)).

$$
\mathrm{NDVI}=\frac{(\text { Band } 4-\text { Band } 3)}{(\text { Band } 4+\text { Band } 3)},
$$

where RED (Band 3) and NIR (Band 4) stand for the spectral reflectance measurements acquired in the visible (RED) and near-infrared (NIR) regions, respectively. NDVI values range is from +0.1 to -0.1 . A zero means no vegetation and close to $+1(0.8-0.9)$ indicates the highest possible density of green leaves. Areas of barren rock, sand, or snow usually show very low NDVI values. Sparse vegetation such as shrubs and grasslands or senescing crops may result in moderate NDVI values. High NDVI values correspond to dense vegetation such as that found in temperate and tropical forests or crops at their peak growth stage [30]. In this case, the NDVI index is extracted based on accessible remote sensing images of the Landsat-7 ETM+ during the years of 1985 to 2015 (refer to Figure 1(d)). Finally, statistical analysis of population growth rates in Istanbul city is calculated during the years of 2000 to 2017 to better understand the trends in climatic parameters according to anthropogenic behaviors affected by growing urbanization in Istanbul area over the time (refer to Figure 1(c)).

\section{Results and Discussion}

Trend analysis of the temperatures and precipitation series using the method of the linear best-fit curve and ManKendall test are applied for subperiods throughout the whole period of 1912-2016. In this case, the first half of studied period (1912-1964) is compared to second half of studied period (1964-2016) for knowing the actual changes in climatic parameters. Also, since the globe on average was hotter in the early 1960s according to fifth assessment report of IPCC in 2013, a comparing analysis between two subperiods of 1912-1980 and 1981-2016 is performed by choosing the turning point in the year of 1980. In this case, the results of basic quality tests for all studied periods showed that the distribution of all-time series at the significance level of $95 \%$ does not follow the randomness principle by use of Run test and the normality principle by using Kolmogorov-Smirnov test for both of Kandilli station and its nearby station of Sariyer. Then, the results of Levene's test of homogeneity and ANOVA test for assessing the absolute homogeneity showed that minimum temperature and precipitation time series of the Kandilli station are homogeneous by comparison between two subperiods' data including 1st and 2nd parts of the entire period of 1912-2016. Also, in the case of assessing the relative homogeneity between two separate data groups including the Kandilli station and its nearby station of Sariyer showed that the average temperature and precipitation time series are homogeneous for the same studied period of 1965-2016. Moreover, results of the homogeneity test showed no homogeneity in the other series whether between meteorological series at the Kandilli station and its nearby station of Sariyer in the same period or between two subperiods of the Kandilli station's series (Table 1). These uneven results of basic tests onto data time periods and subperiods can be affected by urbanization along with global warming effects. So, the population of Istanbul has almost increased by a factor of 17 from 1927 to 2016 and the effects of population growth are changed in the land use and land cover. Also, it is possible to see the different views of Istanbul for vegetation changes by using the Normalized Difference Vegetation Index (NDVI) over the time from 1985 to 2015 (see Figure 1(d)). In this case, adverse effect of urbanization is the decline in forest cover. Many countries have witnessed severe deforestation due to rapid urban growth. On the global scale, the world lost $3 \%$ of its total forest area between 1990 and 2005, with an average $0.2 \%$ decrease per year. Urban areas in Istanbul have also expanded about $87.9 \%$ from 1977 to 2007 , while forest areas declined about $5.4 \%$ in the same period. One of the most significant results of the study was that total forest areas in Istanbul have almost increased about $0.3 \%$ between 2000 and 2007 [31]. The increase of forest areas as opposed to growth in population size may well be explained by the movement of population from rural areas to Istanbul city. Thus, it can provide an opportunity to release human pressure from forest areas, probably resulting in a positive development of forest $[32,33]$. The same period has also witnessed an increase in a rate of 3.1 times in the city's population during the last thirty years. Thus, Istanbul's population is rapidly increasing, and, consequently, the residential settlement is widening. This 


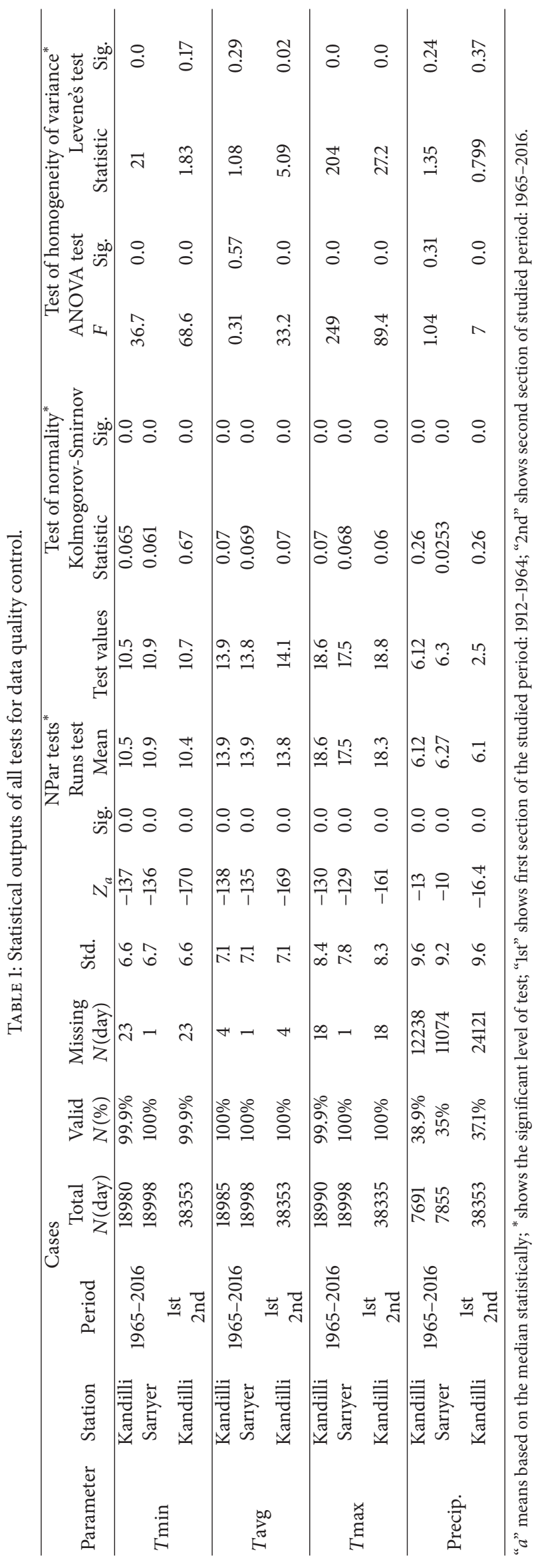




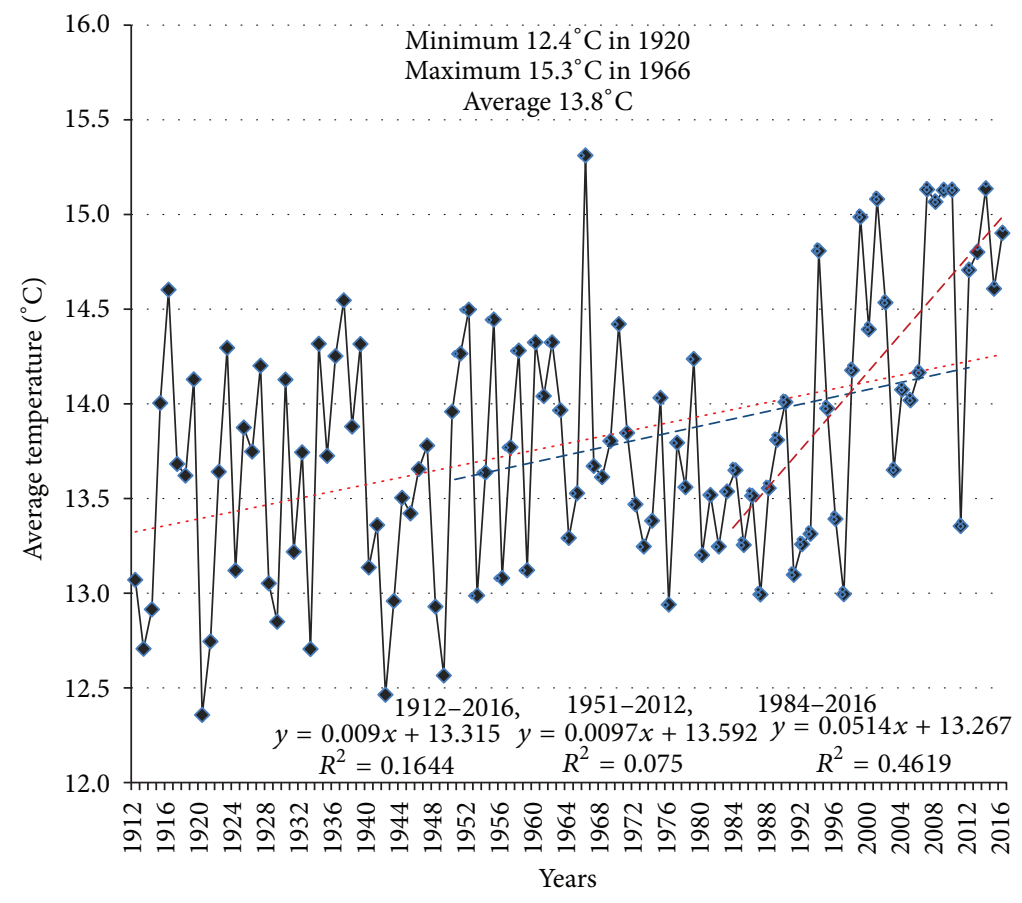

(a)

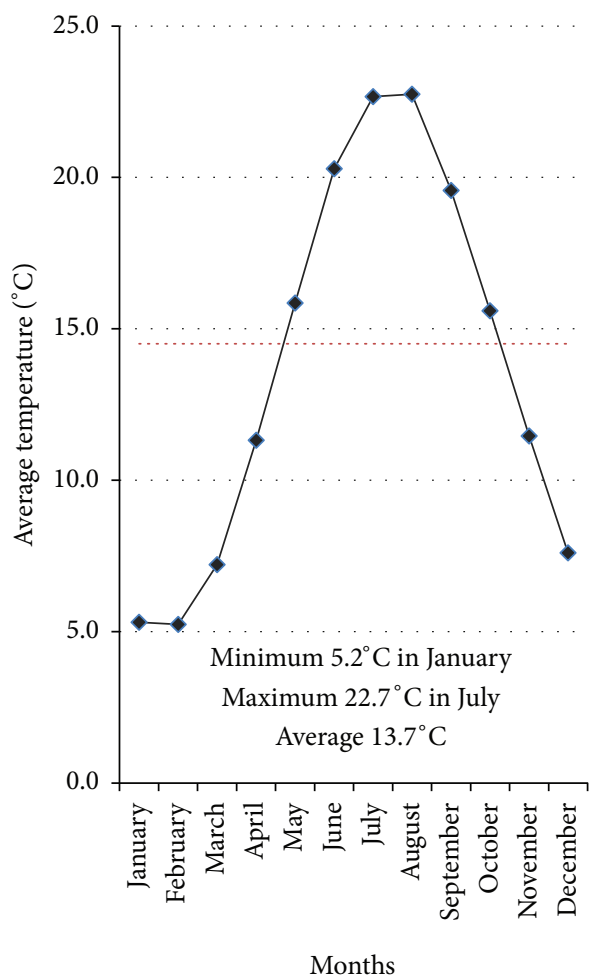

(b)

FIGURE 2: Trend analysis of average annual temperature (a) and average monthly temperature (b).

is the main reason why the forests as Istanbul's life source are being destroyed. Overall, this suggests that progress has been made in Istanbul not only in having sustainable urban growth but also in preserving, restoring, and even expanding forest areas, especially after the year 2000. In the following, after assessing the population growth and land use change in Istanbul, the results obtained from main climatic parameters trend are analyzed for previous decades compared to last decades.

4.1. Temperature. The analysis of average yearly, maximum, and minimum temperature has been carried out using the statistical method of least squares and the MK test at the significance level of $5 \%$ is shown with a dashed line $( \pm 2)$ in Figures 2-5. The results of linear trends and MK rank correlation test showed that there is an increase in the average daily temperature series for the whole period of 1912-2016 in Istanbul (Figure 2(a)). However, this upward trend includes important differences. While there is not any significant change in the annual temperature time series from 1912 to 1944, the upward trend became apparent between 1944 and 1969. A cool period exists in the period of 1969-1993 and, after that, a significant rising trend is pronounced in average annual temperature at the $95 \%$ confidence level. There has been a rise of about $0.94^{\circ} \mathrm{C}$ in the average daily temperature over the last 100 years at Kandilli. Temperature has increased $0.60^{\circ} \mathrm{C}$ in the period of $1951-2016$ and $1.70^{\circ} \mathrm{C}$ in the period of 1981-2016. In this case, the global combined land and ocean surface temperatures show an increase of about $0.89^{\circ} \mathrm{C}\left(0.69^{\circ} \mathrm{C}-1.08^{\circ} \mathrm{C}\right)$ over the period of $1901-2016$ and about $0.72^{\circ} \mathrm{C}\left(0.49^{\circ} \mathrm{C}-0.89^{\circ} \mathrm{C}\right)$ over the period of $1951-2016$ according to fifth assessment report of IPCC in 2013.

Nevertheless, the data time series of Kandilli station shows that the increase in temperature parameter after the 1940 s is in parallel with the beginning of industrialization era in Istanbul. Of course, regime changes in temperature time series on regional scales cannot be totally explained by the nature destruction and pollutant emissions in and around Istanbul, alone. These effects can also be considered as a reflection of the general situation happening in the world on a larger scale. Temperature time series of the Kandilli station shows an annual average about $13.7^{\circ} \mathrm{C}$ and absolute minimum and maximum in 1920 with a value of $12.4^{\circ} \mathrm{C}$ and in 1966 with a value of $15.3^{\circ} \mathrm{C}$, respectively (Figure 2(a)). Owing to the Mediterranean climate of the study area, monthly temperature time series is increased from February to August and is decreased from August to February, reaching a minimum of $5.2^{\circ} \mathrm{C}$ in February and a maximum of $22.7^{\circ} \mathrm{C}$ in August (Figure 2(b)).

A general tendency of a warming trend in the daily temperature series is found for the whole studied period of 1912-2016 by using the least squares regression analysis. Therefore, the trend analysis revealed that the daily average of temperature has increased by a rate of 0.9 for the period from 1912 to 2016 (Figures 3(b1) and 3(b2)). Also, there is a positive trend about $1.49^{\circ} \mathrm{C}$ in daily maximum temperature series during the whole studied period. Furthermore, the increasing trends have notably occurred in two subperiods 


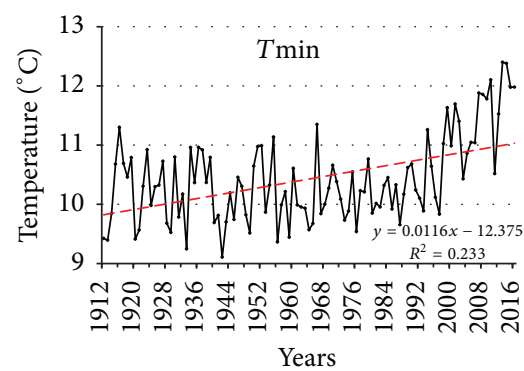

(a1)

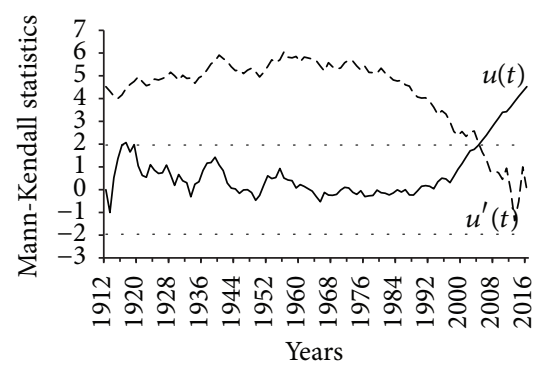

(a2)

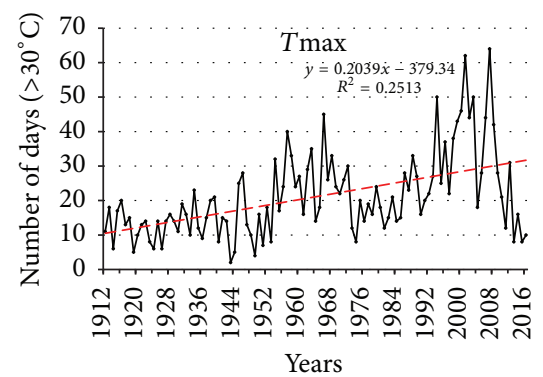

(d1)

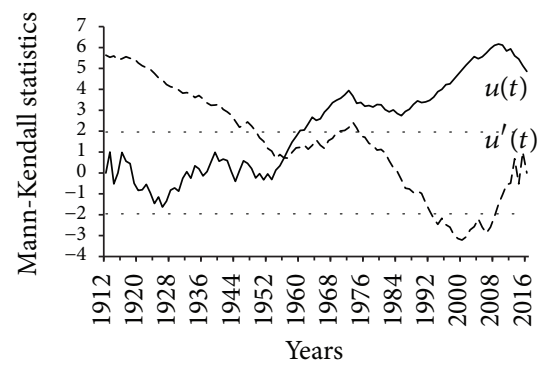

(d2)

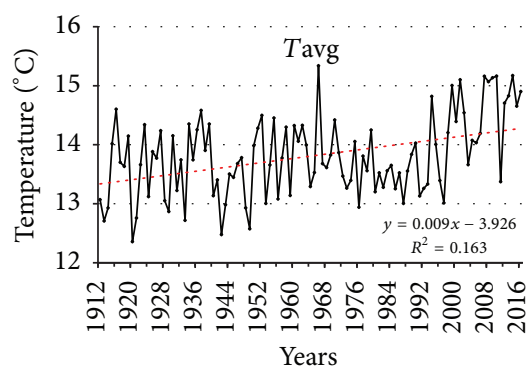

(b1)

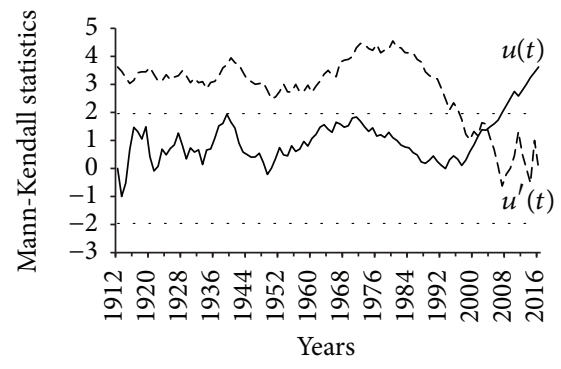

(b2)

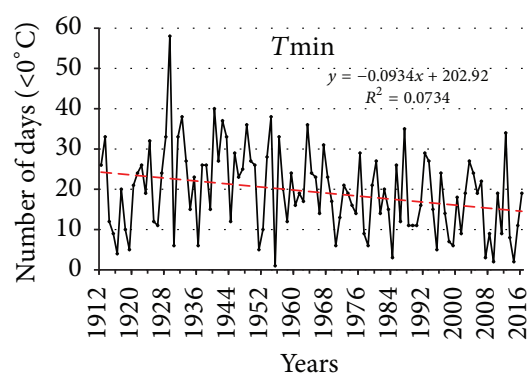

(e1)

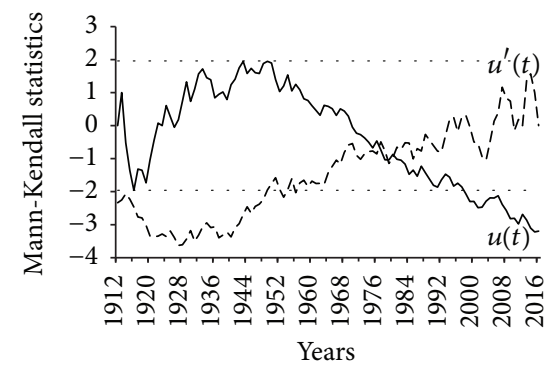

(e2)

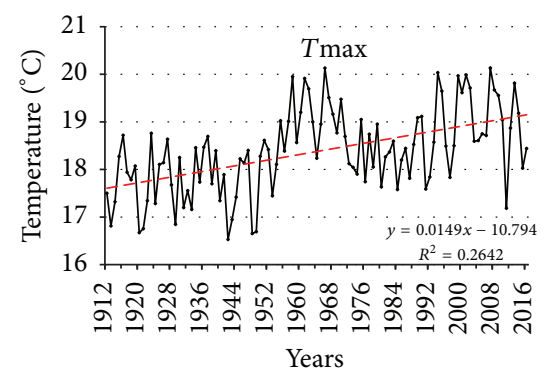

(c1)

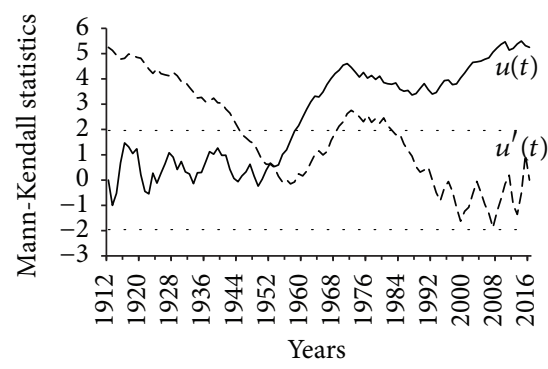

(c2)

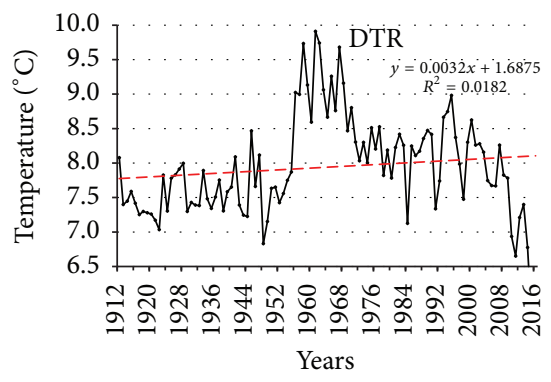

(f1)

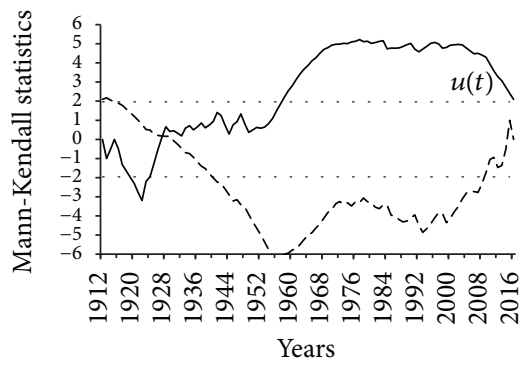

(f2)

FIGURE 3: Trend analysis of the temperatures time series using linear best-fit curve and MK test for daily minimum temperature (a1, a2), daily average temperature $(\mathrm{b} 1, \mathrm{~b} 2)$, daily maximum temperature $(\mathrm{cl}, \mathrm{c} 2)$, number of days with daily maximum temperature $>30^{\circ} \mathrm{C}(\mathrm{d} 1, \mathrm{~d} 2)$, number of days with daily minimum temperature $<0^{\circ} \mathrm{C}(\mathrm{e} 1, \mathrm{e} 2)$, and daily temperature range (f1, $\left.\mathrm{f} 2\right)$.

between 1944 and 1969 and between 1991 and 2016 (Figures $3(\mathrm{cl})$ and $3(\mathrm{c} 2))$. There is a positive trend about $1.1^{\circ} \mathrm{C}$ in daily minimum temperature series during the whole studied period, too, while this positive trend value is smaller than the positive trend value of maximum temperature. The trend of minimum temperature series is stable during the period of 1912-1944. Then, it shows a steady increase during 1942 to 1989, which is most pronounced during 1944-1954. Finally, the rising trends in the minimum temperature series became significant based on MK test's result for the last period of 2003 to 2016. (Figures 3(a1) and 3(a2)). In this case, the minimum temperature shows increasing change for all season where the most increasing change has happened in summer and spring season in all studied periods, respectively (Table 2). Analysis of the number of days having daily maximum temperature higher than $30^{\circ} \mathrm{C}$ for the long time period of 1912 to 2016 by focusing precisely on its subperiods showed that there is almost no trend during 1912-1945, a significant 


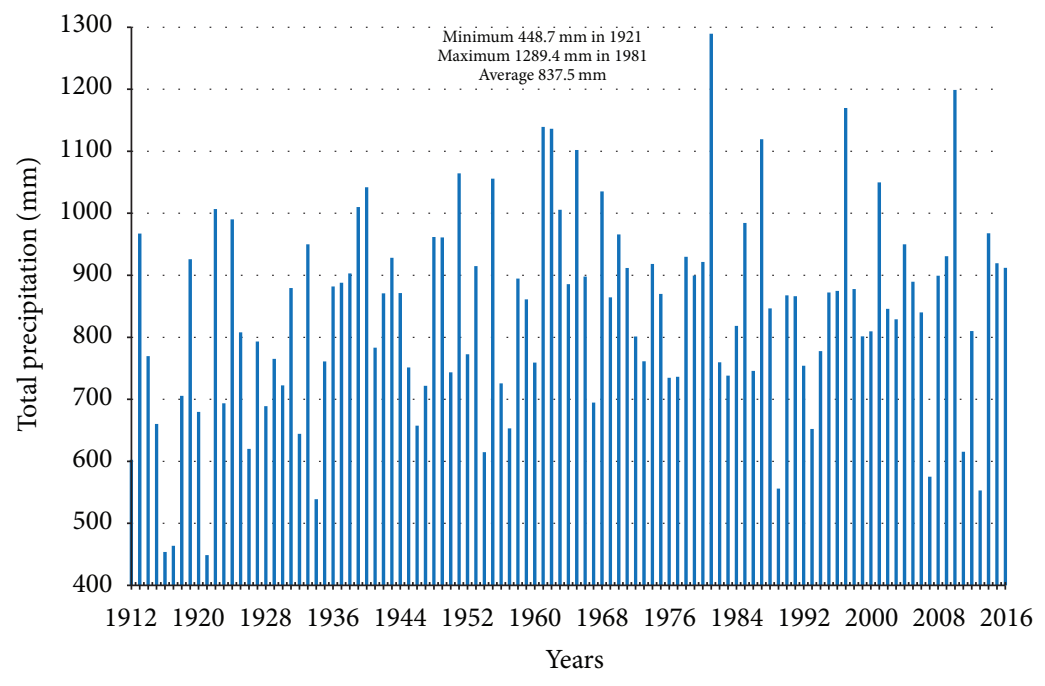

(a)

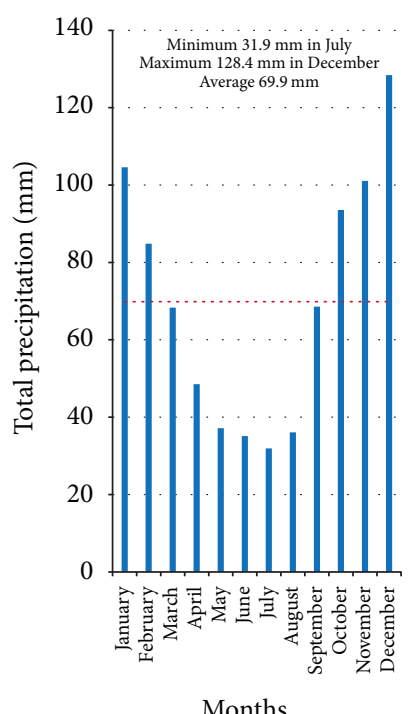

(b)

FIGURE 4: Time series of total annual precipitation (a) and total monthly precipitation (b).

increasing trend during 1945-1969, a relative reduction trend during 1969-1977, an increasing trend during 1977-1992, and a more pronounced increasing trend during 1992-2007 (Figures 3(d1) and 3(d2)). On the other hand, analysis of the number of days with daily minimum temperatures lower than $0^{\circ} \mathrm{C}$ shows a decreasing trend, generally. So, there is a relative increase during 1915-1930, almost no trend during 1930-1954, an increase during 1954-1963, a decrease during 1963-1985, almost no trend during 1985-1995, and a decrease during 1995-2011 by a detailed focus on subperiods of the time series (Figures 3(e1) and 3(e2)). When the daily temperature range in the whole long period is analyzed, an increment can be clearly observed. The situation was stable in the period of 1912-1950. There is an increasing trend during 1950-1970 and an obvious decrement during 1970-1985. Also, there is an increase between 1985 and 2010 (Figures 3(f1) and 3(f2)).

The comparison results between the periods of 1912-1964 and 1965-2016 and the periods of 1912-1980 and 1981-2016 showed that (Table 1) there is an increment in the daily average temperature series about $0.4^{\circ} \mathrm{C}$ for the periods of 1965-2016 $\left(14^{\circ} \mathrm{C}\right)$ compared to previous period of 1912-1964 $\left(13.6^{\circ} \mathrm{C}\right)$ and an increment about $0.5^{\circ} \mathrm{C}$ for the periods of 1981-2016 (14.1 $\left.{ }^{\circ} \mathrm{C}\right)$ compared to previous period of $1912-1980$ $\left(13.6^{\circ} \mathrm{C}\right)$, respectively. In addition, the standard deviation is increased by a coefficient between $0.1^{\circ} \mathrm{C}$ and $0.2^{\circ} \mathrm{C}$ in the whole studied period. The increment of the minimum values in the daily average temperature series is more evident than the maximum values by a mean coefficient of about 6 times for both of studied periods. The minimum value of daily average temperatures in the periods of 1912-1964 and 1965-2016 revealed an increment of $0.6^{\circ} \mathrm{C}$ and $0.8^{\circ} \mathrm{C}$, respectively. The maximum value of daily average temperatures in the periods of 1912-1964 and 1965-2016 showed a decrement of $0.2^{\circ} \mathrm{C}$ and $0.1^{\circ} \mathrm{C}$, respectively. When the monthly values of daily average temperature are analyzed, the highest increment in the periods of 1912-1964 and 1965-2016 is found to be in June at a rate of $1^{\circ} \mathrm{C}$. The highest increment in the periods of 1912-1980 and 1981-2016 appeared to be in June again with a rate of $1.1^{\circ} \mathrm{C}$. Also, there has been temperature decrement in October, November, and December for all studied periods. The highest decrement was in November with a rate of $-0.5^{\circ} \mathrm{C}$ in the periods of $1912-1964$ and $1965-2016$ as well as $-0.4^{\circ} \mathrm{C}$ in the periods of $1912-1980$ and 1981-2016. In this case, the analysis of seasonal values of the daily average temperatures showed that the highest increment in the periods of 1912-1964 and 1965-2016 took place in the summer season at a rate of $0.7^{\circ} \mathrm{C}$. The highest increment in the periods of 1912-1980 and 1981-2016 was found to be in summer again by a rate of $1.1^{\circ} \mathrm{C}$. Also, there was a temperature decrement in the autumn season which was about $-0.10^{\circ} \mathrm{C}$ only for the periods of 1912-1964 and 1965-2016. Analysis of the percentile thresholds of daily average temperatures showed that the temperature increment at the 5 th percentile is $0.5^{\circ} \mathrm{C}$ for the periods of $1912-1964$ and $1965-2016$, while this increment is $0.3^{\circ} \mathrm{C}$ for the periods of $1912-1980$ and $1981-2016$. Therefore, it can be said that the rate of temperature rising has increased further as much as the time is closer to the end years of studied period. Also, these increment values indicate an increase of $0.2^{\circ} \mathrm{C}$ and $0.3^{\circ} \mathrm{C}$ at the 25 th percentile, $0.5^{\circ} \mathrm{C}$ and $0.8^{\circ} \mathrm{C}$ at the 75 th percentile, and $0.6^{\circ} \mathrm{C}$ and $1.1^{\circ} \mathrm{C}$ at the 95th percentile thresholds for the whole studied subperiods of 1912-1964, 1965-2016, 1912-1980, and 1981-2016, respectively. This situation shows that the increment of higher values in the daily average temperatures is greater than the increment of lower values and also this increment is more evident for the periods of 1912-1980 and 1981-2016 compared to the periods of 1912-1964 and 1965-2016.

Comparison of the daily maximum temperature series for two periods of 1912-1964 and 1965-2016 revealed an increment of $0.8^{\circ} \mathrm{C}$ which can be divided into an average 

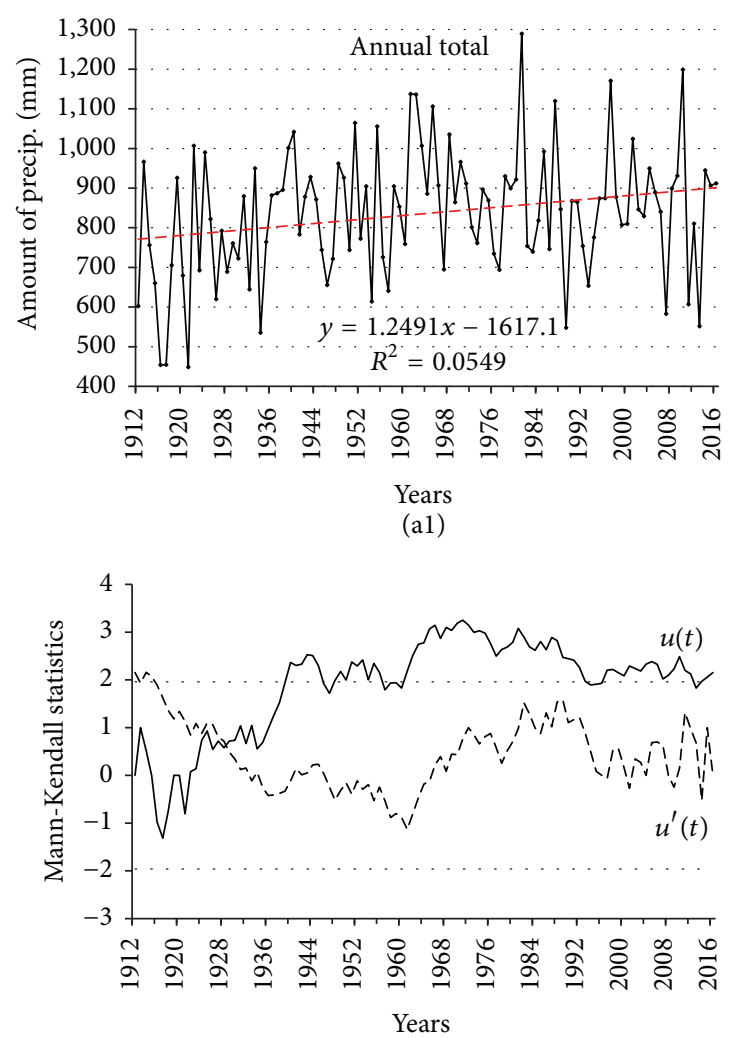

(a2)

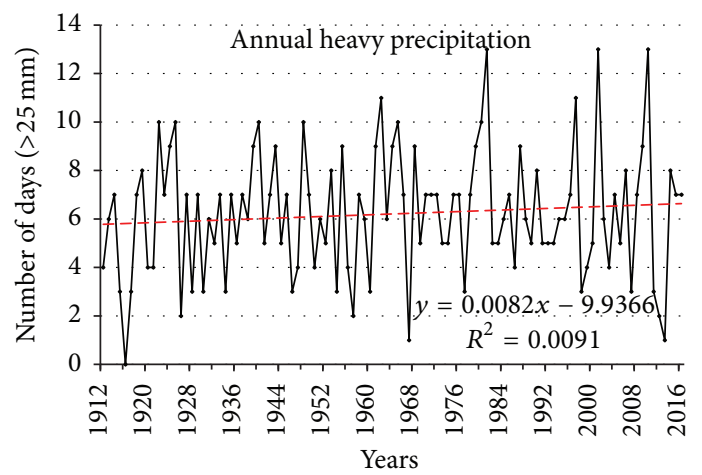

(c1)

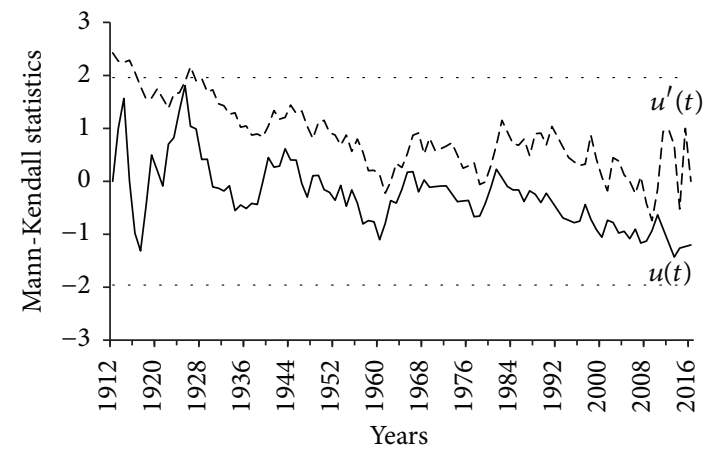

(c2)

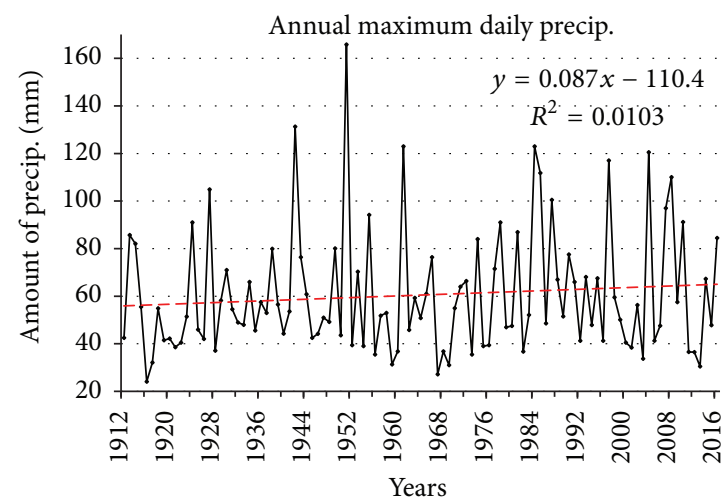

(b1)

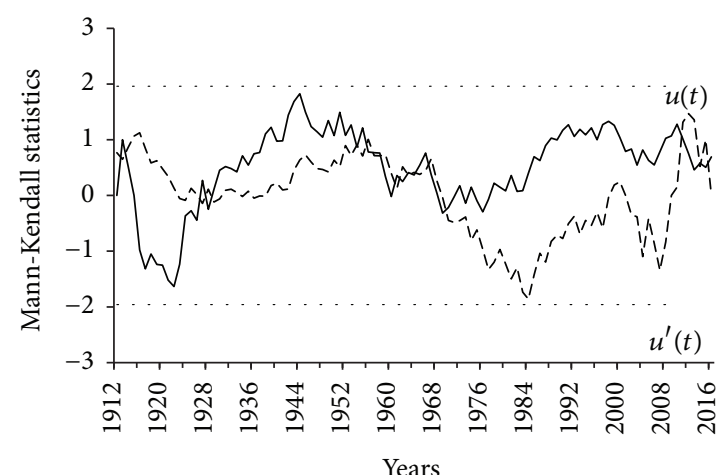

(b2)

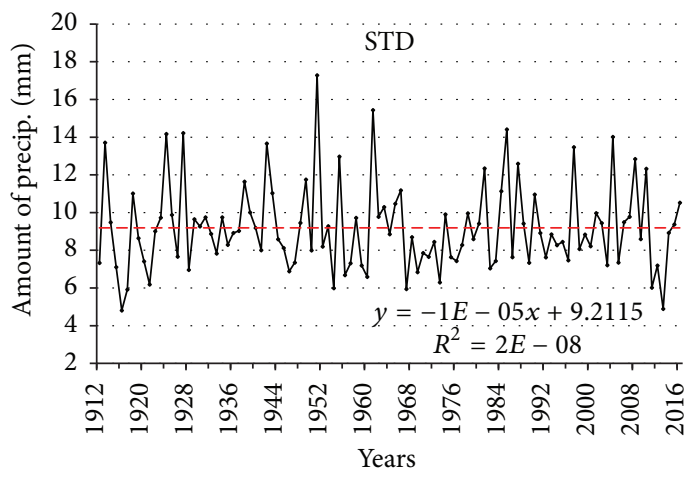

(d1)

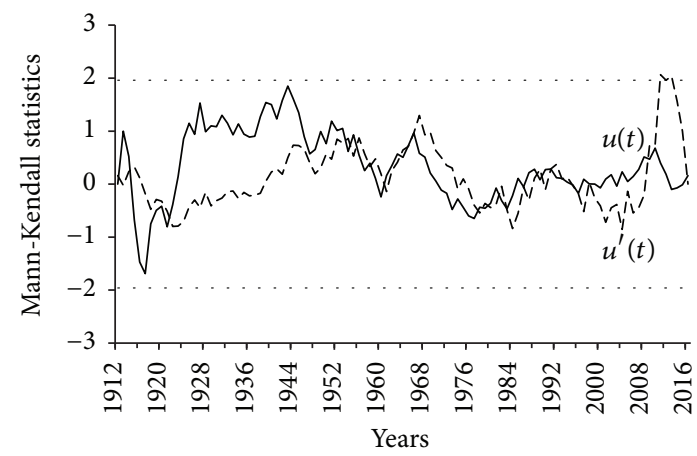

(d2)

FIGURE 5: Trend analysis of the precipitation time series using least squares linear regression and MK trend test for total annual precipitation (a1, a2), daily maximum precipitation (b1, b2), daily maximum precipitation greater than $25 \mathrm{~mm}$ (c1, c2), and standard deviation in the daily precipitation series $(\mathrm{d} 1, \mathrm{~d} 2)$. 


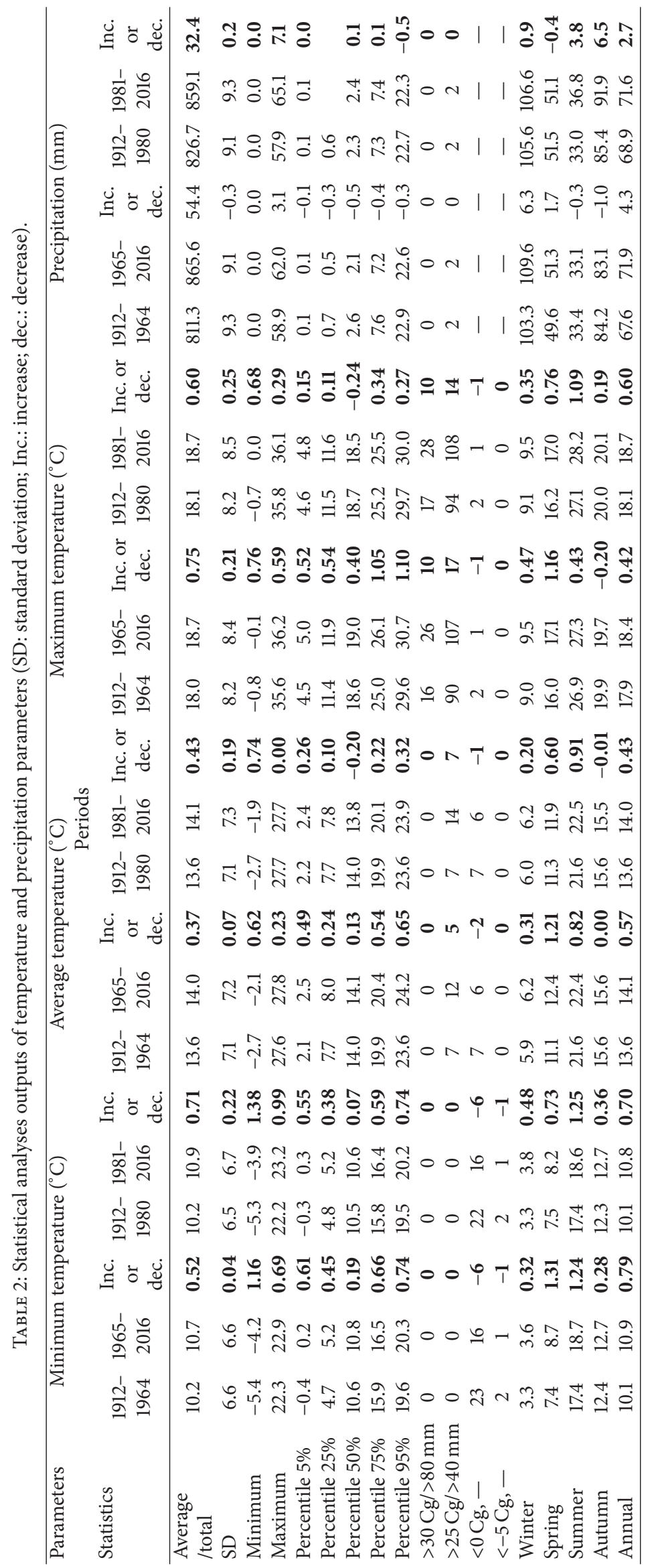


value of $18^{\circ} \mathrm{C}$ for the period of $1912-1964$ and an average value of $18.7^{\circ} \mathrm{C}$ for the period of $1965-2016$. On the other hand, comparison of the daily maximum temperature series for the periods of 1912-1980 and 1981-2016 has revealed an increment of $0.6^{\circ} \mathrm{C}$ with an average value between $18.2^{\circ} \mathrm{C}$ and $18.8^{\circ} \mathrm{C}$ for both of these periods, respectively. In addition, the standard deviation values are increased between $0.2^{\circ} \mathrm{C}$ and $0.3^{\circ} \mathrm{C}$ during the whole studied period. The increment in the minimum values of daily maximum temperature series is more evident than the maximum values. The minimum values of daily maximum temperatures have exhibited an increment of $0.8^{\circ} \mathrm{C}$ for the period of 1965-2016 compared to the previous period of 1912-1964 and also an increment of $0.7^{\circ} \mathrm{C}$ for the period of 1981-2016 compared to the previous period of 1912-1980. Also, the maximum values of daily maximum temperature series exhibited a mean increment of $0.5^{\circ} \mathrm{C}$ for both studied periods. Seasonal analysis of maximum temperature series for both of studied section periods showed that the highest rising temperature has been happened by a value of $1.2^{\circ} \mathrm{C}$ in summer. On the other hand, the lowest increment has happened in the autumn season. The monthly analysis of daily maximum temperature series showed that the highest increment took place during the last months of the spring season and the first month of the summer season in all of the studied periods. When the percentiles of daily maximum temperatures are analyzed, the temperature increment based on the 5 th percentile threshold is $0.5^{\circ} \mathrm{C}$ for the periods of 1912-1964 and 1965-2016, while the increment is $0.3^{\circ} \mathrm{C}$ for the periods of $1912-1980$ and $1981-2016$. This can be considered as an important sign of rising temperature over the time. In this case, the value of percentile thresholds is increased with extending the length of the time period with extending the length of the first section of studied period in favor of last years than the previous ones. In this regard, these values are $0.5^{\circ} \mathrm{C}$ and $0.4^{\circ} \mathrm{C}$ at the 25 th percentile, $1^{\circ} \mathrm{C}$ and $1.1^{\circ} \mathrm{C}$ at the 75 th percentile, and $1.1^{\circ} \mathrm{C}$ and $1.2^{\circ} \mathrm{C}$ at the 95 th percentile for both sections of studied periods, respectively. This situation shows that the increment of higher values in the daily maximum temperatures is greater than lower values.

The comparison analysis of daily minimum temperatures between the periods of 1912-1964 and 1965-2016 and the periods of 1912-1980 and 1981-2016 showed that there is a general increment of $0.5^{\circ} \mathrm{C}$ during the first section periods which can be given as $10.2^{\circ} \mathrm{C}$ and $10.7^{\circ} \mathrm{C}$ for the individual periods of 1912-1964 and 1965-2016 and also a general increment of $0.8^{\circ} \mathrm{C}$ during the second section periods which can be provided as $10.2^{\circ} \mathrm{C}$ and $11^{\circ} \mathrm{C}$ for the individual periods of 1912-1980 and 1981-2016, respectively. In addition, the standard deviation values increased among these section periods from $0^{\circ} \mathrm{C}$ to $0.3^{\circ} \mathrm{C}$. The increment in the minimum values of daily minimum temperature series is more evident than the maximum values. The minimum values of daily minimum temperature series showed an increment of $1.2^{\circ} \mathrm{C}$ from the period of 1912-1964 to 1965-2016 and also an increment of $1.6^{\circ} \mathrm{C}$ from the period of 1912-1980 to 1981-2016. The maximum values of daily minimum temperature series have shown an increment of $0.7^{\circ} \mathrm{C}$ for the section periods of 1912-1964 and 1965-2016 and an increment of $1.2^{\circ} \mathrm{C}$ for the section periods of 1912-1980 and 1981-2016. Overall, the minimum values have had an average increment of $1.4^{\circ} \mathrm{C}$, while the maximum values have had an average increment of $1^{\circ} \mathrm{C}$ during the last century, which can show the higher rate of upward trends in the temperature time series. Monthly analysis of minimum temperature series showed that the highest increment for the section studied periods of 1912-1964 and 1965-2016 has occurred by a value of $1^{\circ} \mathrm{C}$ in June, while the highest increment for the section studied periods of 1912-1980 and 1981-2016 has occurred by a value of $1.6^{\circ} \mathrm{C}$ in August. Meanwhile, there is a temperature decrement in November in both of these periods. However, there is a clear decrement in the first half of these periods in October and December, whereas there is an increment in the second half of these periods. The seasonal analysis of the daily minimum temperature series showed that the highest increment has happened in the summer season with a mean value of $0.7^{\circ} \mathrm{C}$ for the section periods of $1912-1964$ and 1965-2016 and with a mean value of $1.3^{\circ} \mathrm{C}$ for the section periods of 1912-1980 and 1981-2016, respectively. Then, the increasing rate during the summer season became more evident during the recent decades. Analysis of the percentile thresholds of daily minimum temperature series showed that the temperature increment at the 5 th percentile is $0.6^{\circ} \mathrm{C}$ for all studied time periods of 1912-1964, 1965-2016, 1912-1980, and 1981-2016. Also, these increment values indicate an increase of $0.4^{\circ} \mathrm{C}$ and $0.6^{\circ} \mathrm{C}$ at the 25 th percentile, $0.7^{\circ} \mathrm{C}$ and $1.1^{\circ} \mathrm{C}$ at the 75 th percentile, and $0.7^{\circ} \mathrm{C}$ and $1.4^{\circ} \mathrm{C}$ at the 95 th percentile thresholds for the whole studied subperiods of 1912-1964, 1965-2016, 1912-1980, and 1981-2016, respectively. These rising rates in minimum temperature series are more evident for the periods of 1912-1980 and 1981-2016 than the periods of 1912-1980 and 1981-2016. Therefore, it can be said that the rate of temperature rising has increased further as long as the studied time period is closer to the last years.

4.2. Precipitation. Annual average precipitation in Istanbul is $838 \mathrm{~mm}$ with a range of minimum value of $449 \mathrm{~mm}$ in 1921 and a maximum value of $1289 \mathrm{~mm}$ in 1981 based on the observatory data of Kandilli station during the whole studied period from 1912 to 2016 (Figure 4(a)). Also, monthly average precipitation is $69.9 \mathrm{~mm}$ with a range of the minimum of $32.6 \mathrm{~mm}$ in July and the maximum of $128.6 \mathrm{~mm}$ in December during the whole studied time period (Figure 4(b)).

Analysis of the trend in the annual average precipitation time series by the methods of linear regression analysis and MK trend test has shown that periodically there are partial increments and significant differences during the total studied period from 1912 to 2016 (Figures 5(a1) and 5(a2)). But this increment in the precipitation time series is not as clear as the increment in the temperature time series. However, it is obvious in the precipitation time series that there is an increment between the years of 1917 and 1925, a stable condition between the years of 1925 and 1954, an increment between the years of 1954 and 1965, a decrement between the years of 1965 and 1974, an increment between the years of 1974 and 2001, and again a no change situation from 2001 till the end. The trend analysis of the daily maximum precipitation series showed an increment of $2.9 \mathrm{~mm}$ for the periods of 1912-1964 and 1965-2016 as well as an increment 
of $9.3 \mathrm{~mm}$ for the periods of 1912-1980 and 1981-2016. These values indicated that rainfall has increased at a rate of more than three times over the last decades than the previous ones (Figures 5(b1) and 5(b2)). Also, the number of days with daily precipitation greater than $25 \mathrm{~mm}$ presented an increment during the period of 1912-2016, although this is not significant at the confidence level of 0.05 (Figures 5(c1) and 5(c2)). The trend of standard deviation in the daily precipitation time series showed a slowly increasing trend during the total studied period (Figures 5(d1) and 5(d2)).

The comparison of the results of statistical analysis between the daily average rainfall amounts belonging to the periods of 1912-1964 and 1965-2016 with those of the periods of 1912-1980 and 1981-2016 revealed that there is an increment of $78 \mathrm{~mm}$ from the period of 1912-1964 to the period of 1965-2016 and an increment of $38 \mathrm{~mm}$ from the period of 1912-1980 to the period of 1981-2016. In addition, the analysis of standard deviation exhibited a decrement from the period of 1912-1964 to the period of 1965-2016 and an increment from the period of 1912-1980 to the period of 1981-2016 (Table 2). The analysis of monthly average precipitation time series showed that the highest increment has happened in October with $22.7 \mathrm{~mm}$ for the section periods of 1912-1964 and 1965-2016 and with $34.7 \mathrm{~mm}$ for the section periods of 1912-1980 and 1981-2016. On the other hand, the highest decrease took place with a value of $-0.4 \mathrm{~mm}$ during both May and July for the periods of 1912-1964 and 1965-2016 and with a value of $-16 \mathrm{~mm}$ in September for the section periods of 1912-1980 and 1981-2016. The analysis of seasonal average precipitation time series showed that the highest increase occurred in autumn with a value of $7.2 \mathrm{~mm}$ for the section periods of 1912-1964 and 1965-2016 as well as with a value of $6.4 \mathrm{~mm}$ for the periods of 1912-1980 and 1981-2016, respectively. There is no remarkable decreasing change seasonally, except in winter season during the periods of 1912-1980 and 1981-2016. Furthermore, the percentile thresholds of daily average precipitation indicated that there is an insignificant negative trend based on all percentiles and for all studied periods. Overall, the statistical analysis showed that the total average precipitation of Istanbul has increased, while this increasing trend is more pronounced in the previous decades than the last 3 decades. On the other hand, the increasing rate of daily maximum precipitation is more evident during the last 3 decades than the previous decades which can be proven by the increasing frequency of heavy rainfall events in Istanbul.

Generally, the results of trend analysis of Kandilli station during the last 105 years of 1912-2016 showed that there is a warming significant trend in the precipitation time series by using both methods of linear regression analysis and MK trend test. On the contrary, previous climate studies conducted over Turkey put forward that there has been a decreasing trend in annual precipitation time series during the recent decades, regionally. The results of a previously conducted study by using the daily precipitation and temperature data sets of Florya and Göztepe meteorological stations in Istanbul area between 1960 and 2013 showed that most notably the precipitation during the warm periods has decreased, but the frequency of the intense rain has increased and the majority of these episodes of intense rain coincided with the warm periods. Other determinations were the rise in the annual average temperature and the extension of the warm periods in a year. This differentiation of the temperature features can lead to the aggravation of the evaporation and it can be effective for a longer period during the year [15]. Thus, it will make Istanbul be confronted with the much more important problems of water management and flood [34]. Also, the results of the current study for trend analysis in the long period from 1912 to 2016 showed that the most striking spell is between the years of 1968 and 1998 due to the existence of least number of rainfall events in Istanbul. It can be owing to industrialization along with the increasing air pollution as well as irregular urbanization in Istanbul area. In this case, severe droughts taking place during the years of 1988, 1992, 1993, and 2008 have threatened the reservoirs which supplied fresh water of the city. These years were characterized by not having enough rainfall events. These years are also characterized by more persistent high-pressure systems and less occurrence of low-pressure systems in terms of number and strength. As statements made by official institutions, the formation conditions for the atmospheric layer of air pollution due to air pollutant emissions from fossil fuel combustion and industrial activities are more provided during anticyclone or high-pressure system events. Therefore, this leads to warming up and generating an inversion layer in the boundary layer of atmosphere especially over city area [35]. The inversion layer or urban heat island intensity is increasing with the increasing city size and/or population, a phenomenon that was also reported by others [36-38]. Moreover, these last climatic events also have affected some political results beyond natural effects. The most obvious example of this is related to the local election of 1994 in Istanbul. In this case, extreme drought during the summers of 1992 and 1993 has caused groundwater reservoirs to dry up in the city discontinuance of water was experienced for several days or even weeks. In those times, the mayor of Istanbul city has lost the election of 1994 and he realized that this result was due to the people's reaction about the water shortages. Many political reports of that period also support this scientific view.

\section{Conclusions}

Statistical analysis in temperature time series of the Kandilli station from 1912 to 2016 established that there is a notable increase in temperature values after the 1940s which is in parallel with the beginning of industrialization era in Istanbul. There has been a rise about $0.94^{\circ} \mathrm{C}$ in the daily average temperature series since the beginning of the last century. A significant positive trend in the daily maximum temperature series is found about $1.56^{\circ} \mathrm{C}$. Also, there is a positive trend about $0.87^{\circ} \mathrm{C}$ in the daily minimum temperature series. On the other hand, analysis of the number of days with the daily maximum temperature higher than $30^{\circ} \mathrm{C}$ showed that there is an increasing trend. Meanwhile, analysis of the number of days with daily minimum temperatures lower than $0^{\circ} \mathrm{C}$ showed a decreasing trend. The increment in the minimum values of the daily minimum temperature series 
is more evident than the maximum values of this series. In this case, these rising rates in the minimum temperature series are more evident for the section periods of 1912-1980 and 1981-2016 than the section periods of 1912-1964 and 1965-2016. This again shows that there is an increment in the positive temperature trend from past to present decades. The increment in the precipitation time series is not as clear as the increment in the temperature time series due to periodic variability. The trend analysis in the total annual precipitation time series showed that the first significant upward trend has periodically been started from the 1920s, while there is a stable trend from 2001 till 2016. The daily average of rainfall amounts has increased with a value of $58 \mathrm{~mm}$ during the period of 1912-2016. Also, the analysis of heavy precipitation trend showed an increase of $6.1 \mathrm{~mm}$. Overall, the total average precipitation of Istanbul increased, while this increasing trend is more pronounced during the early decades than the last 3 decades. On the other hand, the increasing rate of daily maximum precipitation is more pronounced in the last 3 decades than the previous decades. Then, it was shown that the frequency of heavy rainfall at Istanbul has increased during the recent decades. Thus, the precipitation changes in Istanbul have some differences compared to the general tendency in precipitation trend that was put forward by other studies as a decreasing trend over the whole of Turkey. This result can be expressed as a positive effect of population overgrowth of Istanbul megacity. Comparison of the results in the first half of the study period (1912-1964) with the second half of the study period (1965-2016) showed that both the average temperature and average precipitation have higher values of $13.9^{\circ} \mathrm{C}$ and $878 \mathrm{~mm}$ for the final phase compared to the values of $13.6^{\circ} \mathrm{C}$ and $799 \mathrm{~mm}$ belonging to the initial phase. Therefore, it can be stated that the megacity of Istanbul is directly affected by the climate change and its consequences. In this context, potential risks of climate change in Istanbul megacity under higher temperature conditions can be expressed as the rise in the sea level, increase in the rate of evapotranspiration, and increase in the frequency of heavy rainfall. Also, this city may not be able to handle this uncontrolled population growth and its associated irreversible changes, which is already pushing the natural limits by destroying the environment. Therefore, the local governors of any megacity like Istanbul should give more emphasis on the importance of sustainable urban development. Thus, it is urgent to prepare local and national climate change strategies and action plans for the megacities.

\section{Conflicts of Interest}

The authors declare that there are no conflicts of interest regarding the publication of this paper.

\section{Acknowledgments}

The authors are grateful to the Boğaziçi University, the observatory of Kandilli weather station, and the Earthquake
Research Institute for providing the research data and technical support. The authors also gratefully acknowledge contributions of Assoc. Professor Dr. Yüksel Demirkaya, School of Social Sciences, Marmara University. This work has been supported by Scientific and Technological Research Council of Turkey (TUBITAK) under Grants 113R019 and 106Y258 and by Marmara University (BAPKO) with projects FENE-120314-0066, FEN-C-YLP-090414-0102, FEN-L-2504160180, and FEN-A-100413-0127.

\section{References}

[1] D. R. Easterling, B. Horton, P. D. Jones et al., "Maximum and minimum temperature trends for the globe," Science, vol. 277, no. 5324, pp. 364-367, 1997.

[2] IPCC, Climate Change 2014: IPCC Fifth Assessment Synthesis Report-Summary for Policymakers-an Assessment of InterGovernmental Panel on Climate Change, Cambridge University Press, Cambridge, UK, 2014.

[3] J. Carmin, N. Nadkarni, and C. Rhie, Progress and Challenges in Urban Climate Adaptation Planning: Results of a Global Survey, MIT, Cambridge, UK, 2012.

[4] A. F. Young, "Urban expansion and environmental risk in the São Paulo Metropolitan Area," Climate Research, vol. 57, no. 1, pp. 73-80, 2013.

[5] P. Tian, X. Mu, J. Liu, J. Hu, and C. Gu, "Impacts of Climate Variability and Human Activities on the Changes of Runoff and Sediment Load in a Catchment of the Loess Plateau, China," Advances in Meteorology, vol. 2016, Article ID 4724067, 15 pages, 2016.

[6] R. S. Kovats and K. L. Ebi, "Heatwaves and public health in Europe," European Journal of Public Health, vol. 16, no. 6, pp. 592-599, 2006.

[7] S. Conti, P. Meli, G. Minelli et al., "Epidemiologic study of mortality during the Summer 2003 heat wave in Italy," Environmental Research, vol. 98, no. 3, pp. 390-399, 2005.

[8] J. Kyselý and J. Kim, "Mortality during heat waves in South Korea, 1991 to 2005: how exceptional was the 1994 heat wave?" Climate Research, vol. 38, no. 2, pp. 105-116, 2009.

[9] B. Yan, Z. Xia, F. Huang, L. Guo, and X. Zhang, "Climate change detection and annual extreme temperature analysis of the amur river basin," Advances in Meteorology, vol. 2016, Article ID 6268938, 14 pages, 2016.

[10] E. M. Fischer and R. Knutti, "Anthropogenic contribution to global occurrence of heavy-precipitation and high-temperature extremes," Nature Climate Change, vol. 5, no. 6, pp. 560-564, 2015.

[11] X. Zhang, L. Alexander, G. C. Hegerl et al., "Indices for monitoring changes in extremes based on daily temperature and precipitation data," Climate Change, vol. 2, no. 6, pp. 851-870, 2011.

[12] K. H. Schlünzen, P. Hoffmann, G. Rosenhagen, and W. Riecke, "Long-term changes and regional differences in temperature and precipitation in the metropolitan area of Hamburg," International Journal of Climatology, vol. 30, no. 8, pp. 1121-1136, 2010.

[13] G. Bartolini, M. Morabito, A. Crisci et al., "Recent trends in Tuscany (Italy) summer temperature and indices of extremes," International Journal of Climatology, vol. 28, no. 13, pp. 17511760,2008 
[14] S. C. Sheridan and T. J. Dolney, "Heat, mortality, and level of urbanization: measuring vulnerability across Ohio, USA," Climate Research, vol. 24, no. 3, pp. 255-265, 2003.

[15] M. Tayanç, U. Im, M. Doğruel, and M. Karaca, "Climate change in Turkey for the last half century," Climatic Change, vol. 94, no. 3-4, pp. 483-502, 2009.

[16] H. Toros, "Spatio-temporal variation of daily extreme temperatures over Turkey," International Journal of Climatology, vol. 32, no. 7, pp. 1047-1055, 2012.

[17] H. Toros, "Spatio-temporal precipitation change assessments over Turkey," International Journal of Climatology, vol. 32, no. 9, pp. 1310-1325, 2012.

[18] M. Türkeş, C. Yozgatlıgil, İ. Batmaz et al., "Has the climate been changing in Turkey? Regional climate change signals based on a comparative statistical analysis of two consecutive time periods, 1950-1980 and 1981-2010," Climate Research, vol. 70, no. 1, pp. 7793, 2016.

[19] IPCC, "ummary for Policymakers. In: Climate Change 2013," in The Physical Science Basis. The contribution of Working Group I to the Fifth Assessment Report of the Intergovernmental Panel on Climate Change, Cambridge University Press, Cambridge, UK, 2013.

[20] United Nations, "Department of Economic and Social Affairs, Population Division 2006, World Urbanization Prospects: The 2005 Revision," Working Paper ESA/P/WP/200, 2011.

[21] Y. Demirkaya, Sayılarla Istanbul, ITO, Istanbul, Turkey, 2011.

[22] TUIK, "Address based population registration system results of 2014," Turkish Statistical Institute (TUIK), 2017, http://rapory .tuik.gov.tr/10-03-2015-18:47:27-842632346446643191142126876 .html.

[23] S. Erinç, Climatology and its Methods, Alfa Basım Yayım Dagitim, Istanbul, Turkey, 4th edition, 1965.

[24] O. M. Göktürk, D. Bozkurt, Ö. L. Şen, and M. Karaca, "Quality control and homogeneity of Turkish precipitation data," Hydrological Processes, vol. 22, no. 16, pp. 3210-3218, 2008.

[25] C. Ley and D. Paindaveine, "Runs Tests," in Encyclopedia of Environmetrics, 2012.

[26] A. Ghasemi and S. Zahediasl, "Normality tests for statistical analysis: a guide for non-statisticians," International Journal of Endocrinology and Metabolism, vol. 10, no. 2, pp. 486-489, 2012.

[27] G. V. Glass, “Testing Homogeneity of Variances," American Educational Research Journal, vol. 3, no. 3, pp. 187-190, 1966.

[28] H. B. Mann, "Nonparametric tests against trend," Econometrica, vol. 13, pp. 245-259, 1945.

[29] M. G. Kendall, Rank Correlation Method, Charles Griffin, London, UK, 4th edition, 1975.

[30] H. Turoğlu, "Detection of Changes on Temperature and Precipitation Features in Istanbul (Turkey)," Atmospheric and Climate Sciences, vol. 04, no. 04, pp. 549-562, 2014.

[31] A. Karaburun, A. Demirci, and I.-S. Suen, "Impacts of urban growth on forest cover in Istanbul (1987-2007)," Environmental Modeling \& Assessment, vol. 166, no. 1-4, pp. 267-277, 2010.

[32] K. K. Karanth, L. M. Curran, and J. D. Reuning-Scherer, "Village size and forest disturbance in Bhadra Wildlife Sanctuary, Western Ghats, India," Biological Conservation, vol. 128, no. 2, pp. 147-157, 2006.

[33] G. Çakir, C. Ün, E. Z. Baskent, S. Köse, F. Sivrikaya, and S. Keleş, "Evaluating urbanization, fragmentation and land use/land cover change pattern in Istanbul city, Turkey from 1971 to 2002," Land Degradation \& Development, vol. 19, no. 6, pp. 663-675, 2008.
[34] R. B. Myneni, F. G. Hall, P. J. Sellers, and A. L. Marshak, "The interpretation of spectral vegetation indexes," IEEE Transactions on Geoscience and Remote Sensing, vol. 33, no. 2, pp. 481486, 1995.

[35] Y. S. Unal, H. Toros, A. Deniz, and S. Incecik, "Influence of meteorological factors and emission sources on spatial and temporal variations of PM10 concentrations in Istanbul metropolitan area," Atmospheric Environment, vol. 45, no. 31, pp. 55045513, 2011.

[36] M. Karaca, M. Tayanç, and H. Toros, "Effects of urbanization on climate of İstanbul and Ankara," Atmospheric Environment, vol. 29, no. 23, pp. 3411-3421, 1995.

[37] Y. Ezber, O. L. Sen, T. Kindap, and M. Karaca, "Climatic effects of urbanization in Istanbul: a statistical and modeling analysis," International Journal of Climatology, vol. 27, no. 5, pp. 667-679, 2007.

[38] H. S. Park, "Features of the heat island in seoul and its surrounding cities," Atmospheric Environment (1967), vol. 20, no. 10, pp. 1859-1866, 1986. 

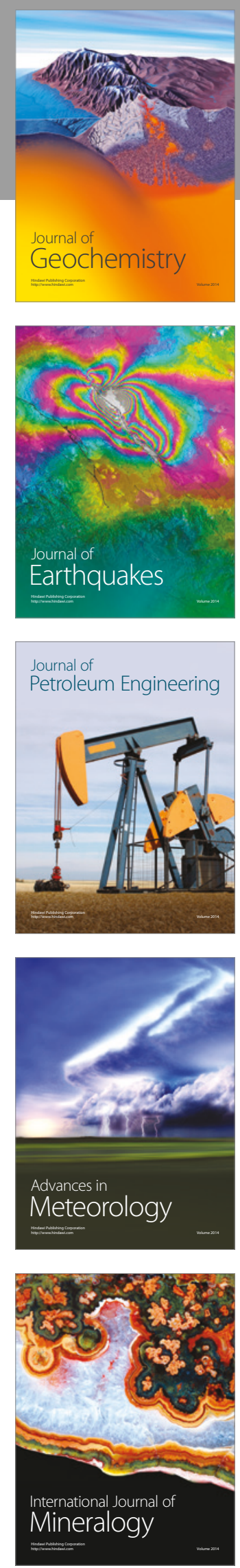
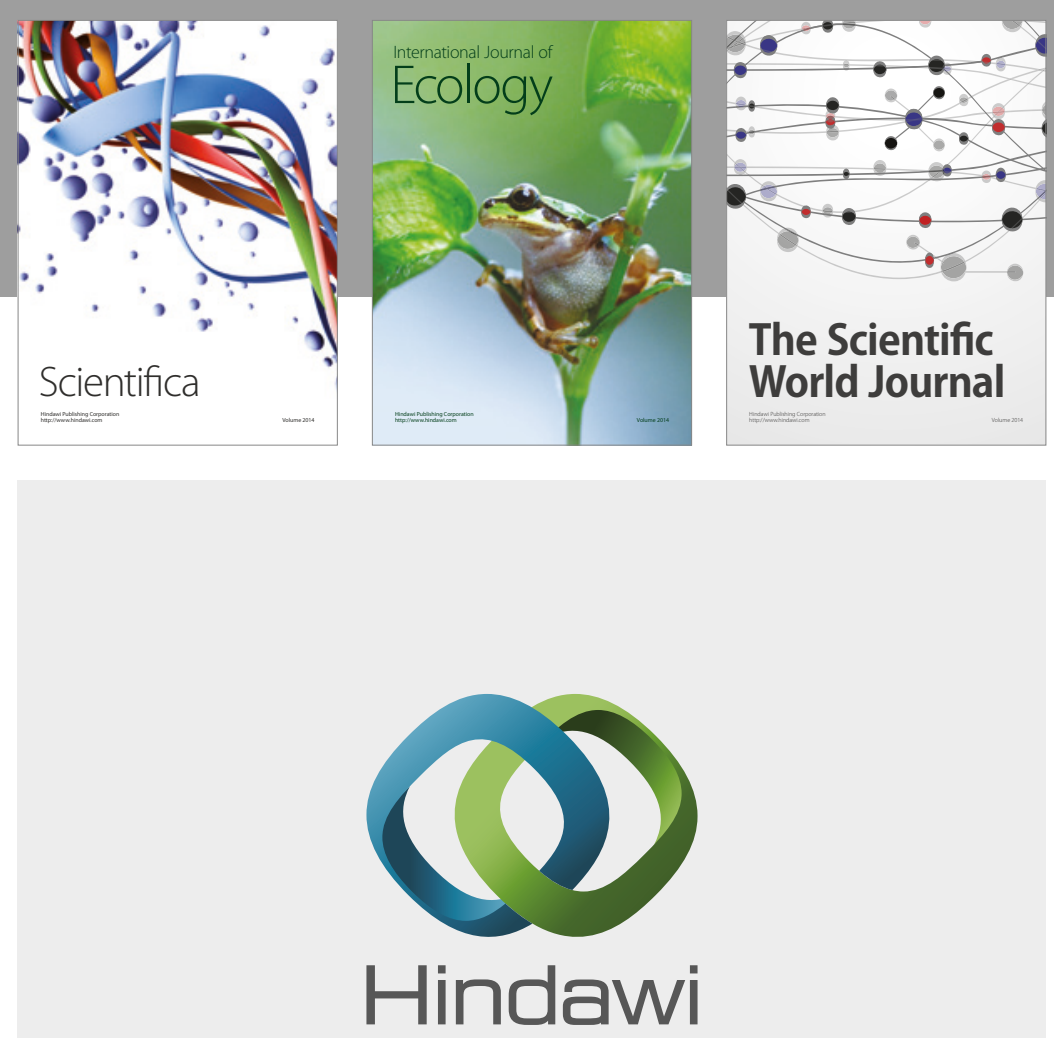

Submit your manuscripts at

https://www.hindawi.com
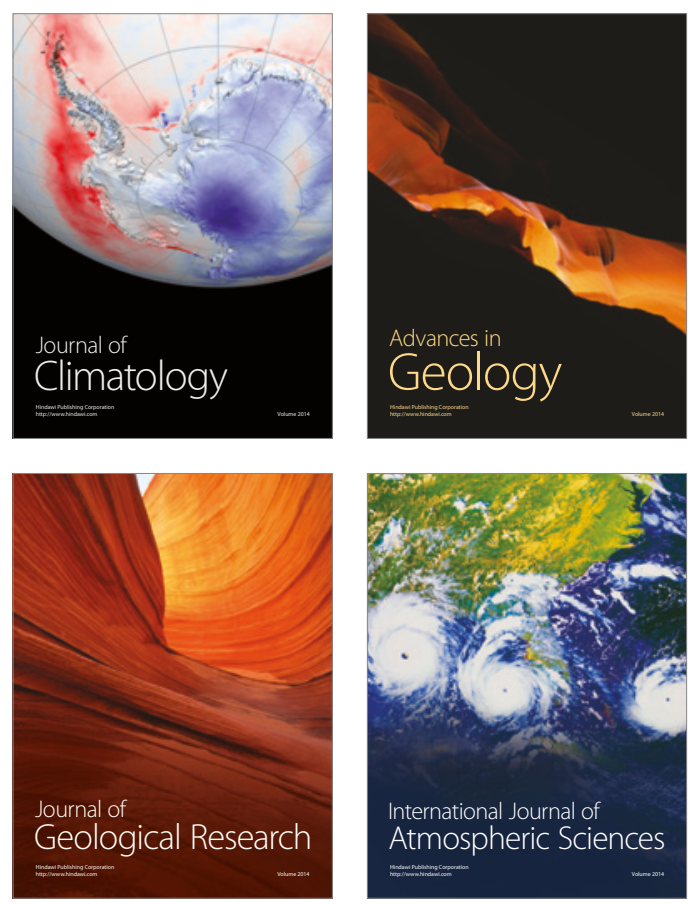

The Scientific

World Journal
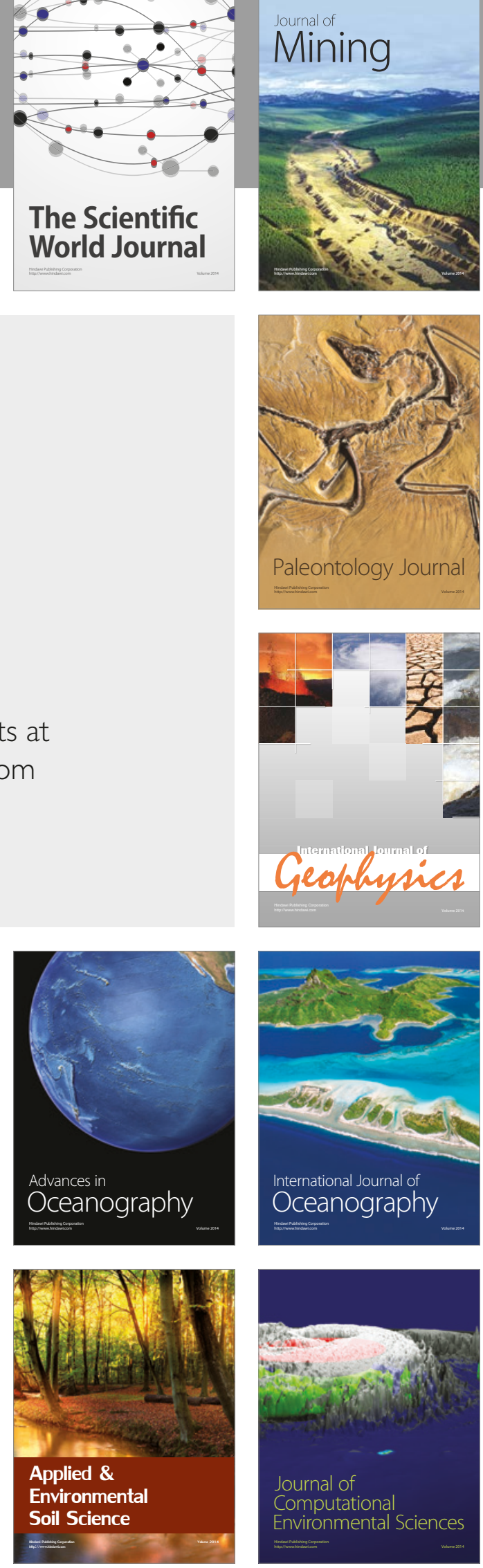